\section{'Jahong': A New Indigenous Korean Chestnut Cultivar with Reddish Burrs}

\author{
Mahn-Jo Kim, Uk Lee, and Yunmi Park ${ }^{1}$ \\ Department of Forest Genetic Resources, Korea Forest Research Institute, \\ 39, Onjeong-ro, Gwonseon-gu, Suwon-si, Gyeonggi-do, Korea
}

Additional index words. Korean native chestnut, cultivar, 'Jahong', nut characteristics, reddish burr

The 'Jahong' chestnut (Castanea crenata Siebold \& Zucc) was released from Korean native chestnut trees by the Korea Forest Research Institute (KFRI) to develop cultivars with desirable nut characteristics such as high sweetness, easy peeling, and a hard kernel in 2009. This cultivar was first selected from a natural population in 2001 , and the preliminary and advanced trials for evaluation were carried out from 2003 to 2007. 'Jahong' is a medium-ripening cultivar with reddish burrs distinct from any other cultivars between late July and mid-August before ripening. With its distinct red color, this cultivar could provide beauty in ornamental tree cultivation. 'Jahong' is a suitable cultivar for eating raw and making roasted peeled products, because its soluble solid content is $16.3 \%$, kernel hardness is $10.3 \mathrm{~kg} \cdot \mathrm{cm}^{-2}$, and pellicle removability is $90.0 \%$, which are much higher than those of the control cultivar, Arima (Castanea crenata Siebold \& Zucc). This new cultivar is also suitable as a pollinator for the improvement of nut quality such as sweetness and pellicle removability.

\section{Origin}

The 'Jahong' (Castanea crenata Siebold \& Zucc) chestnut was selected in 2001 from indigenous individuals located at Maegokri, Gonggunmyun, Hoengsunggun, and Gangwondo, Republic of Korea, for its superior nut quality and unusual reddish burrs. Since 2001, the cultivar has produced a sweet, firm fruit uniformly throughout the fruiting season and has shown resistance to chestnut blight disease.

\section{Description and Performance}

We investigated indigenous old chestnut trees (more than 60 years) for candidates to develop new cultivars for 3 years from 2001 in 24 regions of five provinces in the Republic of Korea. After such efforts, the line with reddish burrs before ripening and good nut quality was initially selected out of 237 candidates. Using the veneer grafting technique, the selected line was first propagated in the experiment nursery

Received for publication 24 July 2014. Accepted for publication 14 Oct. 2014.

${ }^{1}$ To whom reprint requests should be addressed; e-mail pym5250@forest.go.kr. in the Department of the KFRI in 2002. We investigated morphological characteristics such as burrs, shoots, leaves, flowers, and nuts and phenological characteristics such as time of leaf bud burst, flowering, and nut ripening for 4 years. Five clones with nut characteristics such as high sweetness (14\% or greater), easy peeling ( $85 \%$ or greater), and hard kernel $\left(9 \mathrm{~kg} \cdot \mathrm{cm}^{-2}\right.$ or greater) were finally selected and compared with the cultivar Arima $(C$. crenata). This cultivar, Arima (C. crenata), first introduced from Japan, has large fruit, good yields, and excellent plant vigor and has been generally cultivated in Korea for a long time (Chung, 2006). We evaluated the clones from 2007 to 2009 for fructification characteristics, harvesting time, yield, and morphological nut characteristics and nut traits according to guidelines for the conduct of tests for distinctness, homogeneity, and stability in the chestnuts from France (Castanea sativa Mill.) (Rural Development Administrator, 1995). For soluble solid content, we measured the fruit juice extracted from the nuts with a refractometer (RA-510; Kyoto Electronics MFC. Co., Ltd., Kyoto, Japan) within $48 \mathrm{~h}$ after randomly selecting 20 good
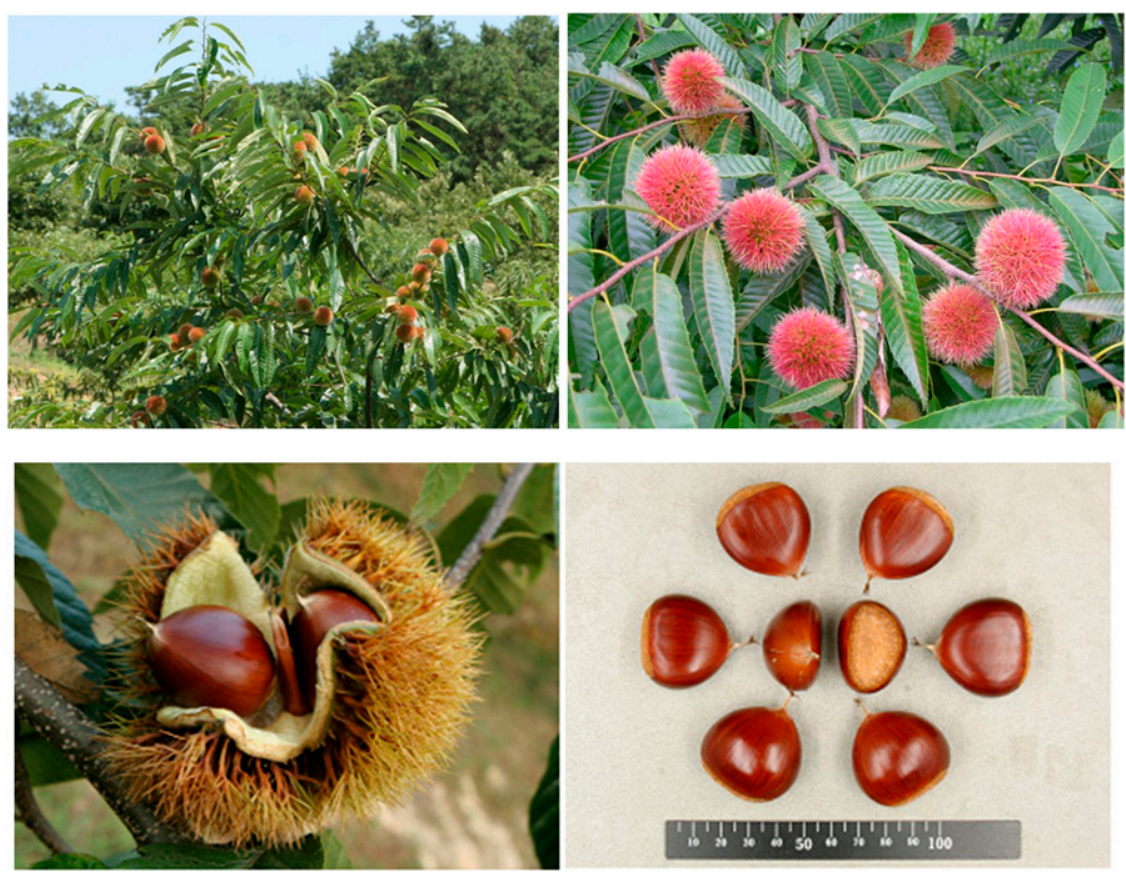

Fig. 1. Fructification of 'Jahong' and reddish burr (top right) in mid-August. harvested nuts. We examined hardness for kernels without shells with a material tester (Ez-Test/CE; Shimadzu Co., Kyoto, Japan). The proportion of polyembryonic nut was converted into a percentage through the detected nut number. Pellicle removability was estimated by converting the nut number, in which the pellicle is removed perfectly from the kernels of deep-fried nuts, into a percentage. The values provided are the average of the data collection for 3 years (2007-09).

The cultivar Jahong shows a half-erect tree shape and vigorous tree force having many bearing branches, whereas 'Arima' shows a spreading shape not having enough bearing branches. Also, the cultivar was observed to have resistance to chestnut blight disease (data not shown). The leaf morphological characteristics of 'Jahong' show a mucronate incision shape of the leaf margin and a rounded shape of the leaf blade base, whereas the standard cultivar Arima has a dentate incision shape of the leaf margin and the same shape as the 'Jahong' of leaf blade base. The winter bud of the new cultivar is dark red in color with dense hairs, whereas the dormant bud is hairless and reddish brown in color, the same as the standard cultivar Arima. As remarkable morphological characteristics, the top site of a first-year shoot and thorns of chestnut burrs before ripening is red in color between late July and mid-August (Fig. 1). The leaf bud of the 'Jahong' bursts $\approx 27$ Apr. at about the same period as the 'Arima'. The flowering period of male catkins is from 15 June to 26 June with a full bloom period from 18 June to 22 June. The flowering period of female catkins is from 10 June to 23 June with a full bloom period from 15 June to 18 June (Table 1). 'Jahong' is considered to be a medium-flowering cultivar, same as the Arima cultivar, which has been widely cultivated in Korea. 
Table 1. The phenological characteristics of 'Jahong'.

\begin{tabular}{|c|c|c|c|c|c|c|c|c|c|}
\hline \multirow[b]{2}{*}{ Cultivars } & \multirow[b]{2}{*}{$\begin{array}{c}\text { Time of } \\
\text { leaf } \\
\text { bud burst }\end{array}$} & \multicolumn{4}{|c|}{ Male catkins } & \multicolumn{4}{|c|}{ Female catkins } \\
\hline & & $\begin{array}{l}\text { Flowering } \\
\text { beginning }\end{array}$ & $\begin{array}{c}\text { Full } \\
\text { bloom } \\
\text { beginning }\end{array}$ & $\begin{array}{l}\text { Full } \\
\text { bloom } \\
\text { end }\end{array}$ & $\begin{array}{c}\text { Flowering } \\
\text { end }\end{array}$ & $\begin{array}{l}\text { Flowering } \\
\text { beginning }\end{array}$ & $\begin{array}{c}\text { Full } \\
\text { bloom } \\
\text { beginning }\end{array}$ & $\begin{array}{l}\text { Full } \\
\text { bloom } \\
\text { end }\end{array}$ & $\begin{array}{c}\text { Flowering } \\
\text { end }\end{array}$ \\
\hline Jahong & 27 Apr. & 15 June & 18 June & 22 June & 26 June & 10 June & 15 June & 18 June & 23 June \\
\hline Arima & 29 Apr. & 10 June & 15 June & 18 June & 23 June & 10 June & 14 June & 18 June & 20 June \\
\hline
\end{tabular}

Table 2. Flowering and fructification characteristics of 'Jahong'.

\begin{tabular}{lcccc}
\hline Cultivars & $\begin{array}{c}\text { No. of female } \\
\text { catkins per } \\
\text { bearing branch }\end{array}$ & $\begin{array}{c}\text { No. of bearing } \\
\text { branches per bearing } \\
\text { mother branch }\end{array}$ & $\begin{array}{c}\text { No. of total burrs } \\
\text { per bearing mother } \\
\text { branch }^{y}\end{array}$ & $\begin{array}{c}\text { No. of burrs per } \\
\text { bearing branch }\end{array}$ \\
Jahong & $2.0 \pm 0.50 \mathrm{a}^{\mathrm{z}}$ & $3.3 \pm 1.05 \mathrm{a}^{\mathrm{z}}$ & $6.8 \pm 2.78 \mathrm{a}^{\mathrm{z}}$ & $2.0 \pm 0.57 \mathrm{a}^{\mathrm{z}}$ \\
Arima & $1.8 \pm 0.48 \mathrm{~b}$ & $2.2 \pm 0.82 \mathrm{~b}$ & $2.6 \pm 1.13 \mathrm{~b}$ & $1.2 \pm 0.28 \mathrm{~b}$ \\
\hline
\end{tabular}

${ }^{2}$ Means \pm SD done by Student's $t$ test at $P=0.05$ on five plants per cultivar over 3 years ( 20 branches/plant); similar letters within a column indicate no significant difference.

${ }^{y}$ Measured during the first week of September.

${ }^{x}$ Measured during the second week of June.

Table 3. Yield and morphological characteristics of 'Jahong'.

\begin{tabular}{|c|c|c|c|c|}
\hline Cultivars & Yield $(\mathrm{kg} / \text { tree })^{\mathrm{y}}$ & Nut shape & Nut ht/nut width ${ }^{y}$ & Hilum length/nut widthy \\
\hline$\overline{\mathrm{Jah}}$ & $6.2 \pm 1.05 \mathrm{a}$ & Rounded triangular & $0.86 \pm 0.03 \mathrm{a}^{\mathrm{z}}$ & $\pm 0.04 \mathrm{a}^{\mathrm{z}}$ \\
\hline Arima & $6.4 \pm 0.27 \mathrm{a}$ & Oblate & $0.91 \pm 0.04 \mathrm{~b}$ & $0.60 \pm 0.04 \mathrm{a}$ \\
\hline
\end{tabular}

${ }^{\mathrm{z}}$ Means \pm SD done by Student's $t$ test at $P=0.05$ on five plants per cultivar over 3 years (20 nuts/plant); similar letters within a column indicate no significant difference.

${ }^{y}$ Measured during the fourth week of September; measured at 8 years old for yield.

Table 4. Nut characteristics of 'Jahong'.

\begin{tabular}{|c|c|c|c|c|c|}
\hline Cultivars & Nut $w^{y}{ }^{y}(g)$ & $\begin{array}{l}\text { Soluble solid } \\
\text { content }^{\mathrm{y}}(\%)\end{array}$ & $\begin{array}{c}\text { Kernel } \\
\text { hardness } \\
\left(\mathrm{kg} \cdot \mathrm{cm}^{22}\right)\end{array}$ & $\begin{array}{c}\text { Percent of } \\
\text { Polyembryonic } \\
\text { nuts }^{y}(\%)\end{array}$ & $\begin{array}{c}\text { Pellicle } \\
\text { removability }(\%)\end{array}$ \\
\hline Jahong & $13.8 \pm 2.91 \mathrm{a}^{\mathrm{z}}$ & $16.3 \pm 4.03 \mathrm{a}^{\mathrm{z}}$ & $10.3 \pm 1.99 \mathrm{a}^{z}$ & $0.0 \mathrm{a}^{\mathrm{z}}$ & $90.0 \pm 7.70 \mathrm{a}^{\mathrm{z}}$ \\
\hline Arima & $19.2 \pm 2.91 \mathrm{~b}$ & $13.4 \pm 3.62 \mathrm{~b}$ & $7.8 \pm 2.48 \mathrm{~b}$ & $1.1 \pm 2.90 \mathrm{~b}$ & $54.6 \pm 9.97 \mathrm{~b}$ \\
\hline
\end{tabular}

${ }^{2}$ Means \pm SD done by Student's $t$ test at $P=0.05$ on five plants per cultivar over 3 years ( 20 nuts/plant); similar letters within a column indicate no significant difference.

${ }^{y}$ Measured during fourth week of September.

'Jahong' has 2.0 more female catkins than 'Arima'. The number of bearing branches, burrs per bearing mother branch, and burrs per bearing branch are also more than those of 'Arima' (Table 2). So the total yield of 'Jahong' with an 8-year-old tree capable of producing $6.2 \mathrm{~kg}$ of nuts was similar that of a standard cultivar (Table 3 ). This cultivar is also a medium-ripening cultivar and optimally harvested $\approx 24$ Sept. 'Jahong' has short and dense burrs, dark brown nuts, a rounded triangular shape, a nut height-to-nut width ratio of 0.86 , and a hilum length-to-nut width ratio of 0.59 . So, the nuts from 'Jahong' can be distinguished from those of other cultivars and more easily processed for peeled products because of their unique shape (Table 3 ). Nut weight is $13.8 \mathrm{~g}$ with a soluble solid content of $16.3 \%$ within $48 \mathrm{~h}$ after harvesting, a kernel hardness of $10.3 \mathrm{~kg} \cdot \mathrm{cm}^{-2}, 0.0 \%$ polyembryonic nuts, and $90.0 \%$ pellicle removability (Table 4). Because the important factors in deciding nut quality such as the soluble solid content, kernel hardness, and pellicle removability were higher than in existing cultivars, we predict that this cultivar has great potential product value for eating raw and making roasted products. Also, because polyembryonic nuts are not high marketability products, 'Jahong' with a low percent of polyembryonic nuts has potential product value (Kim et al., 2003).

\section{Notes in Cultivation}

'Jahong' is differentiated from other cultivars because of its reddish burrs before ripening, and this characteristic could make this new cultivar useful as an ornamental tree between late July and mid-August. It is also easy to distinguish from most oblate-shaped cultivars, because the nut shape is an obvious rounded triangular form for picking in harvest season. However, because 'Jahong' is a cultivar bearing heavy fruiting in young 6-year-old trees, this cultivar could show small nuts and annual fructification. So, the cultivar does demand proper pruning and fertilizer control to maintain tree vigor continuously. 'Jahong' is suitable for silt loam, which is deep in soil depth and contains proper moisture. This cultivar is also more suitable for extensive cultivation that uses small inputs of labor, fertilizers, and capital relative to the land area being farmed because of the small nut size compared with existing cultivars with large nuts. Moreover, 'Jahong' with good nut quality is suitable for planting for pollination purposes in chestnut plantations, because the effects of pollen could be expressed in fresh fruit through nut characteristics such as sweetness and the peeling of seedcoat (Mckay and Crane, 1939; Serdar et al., 2011).

\section{Availability}

On 15 Oct. 2013, the new cultivar Jahong was granted cultivar protection by seed industry law (Korea Seed and Variety Service, grant number 44). Nurseries interested in a propagating program may contact the Korea Forest Research Institute, Chestnut Research Center, 39, Onjeong-ro, Gwonseon-gu, Suwon-si, Gyeonggi-do, Korea, or otttr@forest.go.kr.

\section{Literature Cited}

Chung, K.S. 2006. Chestnut cultivars in Korea Korea Forest Research Institute, Suwon, Korea. p. $105-109$.

Kim, M.J., U. Lee, M.S. Hwang, M.H. Lee, and S.C. Kim. 2003. Nut characteristics of chestnut cultivars cultivated in Korea. Proc. of the 2003 Summer Meeting of the Korean Forest Society. p. $322-324$

Mckay, J.W. and H.L. Crane. 1939. Xenia in the chestnut. Science 89:348-349.

Rural Development Administrator. 1995. Manual for agricultural investigation. RDA, Suwon, Korea.

Serdar, U., H. Demirsoy, and L. Demirsoy. 2011. A morphological and phenological comparison of chestnut (Castanea) cultivars 'Serdar' and 'Marigoule'. Australian Journal of Crop Science 5:1311-1317. 